\title{
Fail again, fail better: the case for formative assessment in first year undergraduate creative practice-based modules.
}

\begin{abstract}
This article identifies an intrinsic paradox in creative practice-based degree programmes that use outcome-led curricula and summative assessment in their first year undergraduate practical modules. Offering a personal reflection by two teachers-practitioners, this article is not a comprehensive study of current practices but rather informed by specific teaching experiences in UK higher education setting. It will argue that it is detrimental to have specific learning outcomes at such an early stage of students' development where trial and error should be part of an organic and experiential learning process. It will also question more broadly the usefulness of summative assessment in process-led subjects such as acting and creative writing, and suggest that this kind of assessment may be in tension with the methodologies of these disciplines. It will develop the argument by using an experiential descriptive case study to propose an example of an alternative, “utopian blueprint”, practical, process-led first year acting module. This utopian module proposes pedagogical principles which are interchangeable with other practice-led subjects such as creative writing. This blueprint design favours the process-led curriculum, and thus lends itself to formative assessment. Not only does formative assessment thereby offer a better fit with first year students' learning experiences, but it also mirrors professional relationships such as actor-director/writer-editor associations in the creative industries, thus preparing students for life outside the academy. Finally, the article foregrounds the importance of utilising the benefits of the 'practice as research' methodology for practitioner-lecturers in Higher Education.
\end{abstract}




\section{Context}

"How can my heart and soul be worth 56\%?"

Most, if not all, teachers of creative practice-based degree programmes have encountered students who are angry, crushed, or just mystified by the marks they receive at the end of a formally-assessed academic module. Even students who are surprised and delighted by their mark often say, "but I've no idea how I did it.” This happy accident can occur when students stumble across their own innate aptitude without recognising the tools that they have used. One can understand such puzzlement since what we are trying to assess is not just, in the words of Strasberg, "book learning”, but "the ability to comprehend the workings of the human soul". ${ }^{1}$ This means that students can feel their efforts have been in vain because their hard work does not always translate into the academic grade that they believe they deserve. They are subject to the paradox of the summative learning outcome model of the academy whereby, on paper they are deemed to have achieved a benchmark, whereas in practice they have not necessarily gained meaningful insights into the complexities of creative processes. This means that they can pass a module with no guarantee that they have understood and can replicate the characteristics of successful creative practice.

In our experience as lecturers in drama and creative writing, this tension is most apparent in first year modules where the majority of students are making a leap into more independent and critically rigorous modes of learning. Pedagogically-speaking, we are talking about the impact on assessment of simple or surface learning versus complex or deep learning. By surface learning, we mean the ability to retain and reproduce a fact, for example taking notes in a lecture and then reproducing them in an exam. By deep learning we mean the ability to recognise and replicate complex processes, for example, the ability to create convincing characters. While deep learning is desirable in all academic disciplines, the differences and tensions between deep and surface learning are particularly visible in degree programmes involving creative practice, which in general are relatively recent additions to higher education provision, and are delivered by lecturers who are professional practitioners, subscribing to the 'practice as research' model of intellectual enquiry. Indeed, practice as research is now an acceptable route to an academic career. This shift in emphasis brings with

\footnotetext{
${ }^{1}$ Lee Strasberg, A Dream of Passion: The development of The Method ed. Evangeline Morphos (New York: Plume Penguin Group, 1988), xii.
} 
it another issue: the teacher-practitioner's potential reluctance to play the "grade game". This is because practitioners, by definition, work on the assumption that process is crucial in the development of a creative product and are, therefore, at ease with formative assessment.

Prior to offering a potential solution to this pedagogical problem, we will briefly situate our discussion within recent academic discourse.

\section{Current Debates}

Over the past decade or so, there have been a number of important reforms in assessment practices in Higher Education. In comparison with our own experiences of undergraduate study, the students we teach have never been so well-informed about what is expected of them and the criteria against which they are being assessed. The now accepted and widely used ideas behind constructive alignment and the SOLO taxonomy (Structure of the Observed Learning Outcome) have been developed by Biggs, who proposes that "A good teaching system aligns teaching method and assessment to the learning activities stated in the objectives, so that all aspects of this system are in accord in supporting appropriate student learning”. ${ }^{2}$ However, as the frustrations of our own teaching and assessment practices attest, the complexities and peculiarities of assessing creative practice mean that the SOLO taxonomy is not so easily employed. It is particularly worth noting the Imaginative Curriculum Project (2002) and the work of Peter Knight who states that it is neither possible to "plan for nor measure complex learning in the ways that we treat simple learning". 3

Paul Kleinman’s research on creativity and assessment has been ground-breaking; in particular his detailed work on the creative individual, creative product and creative environment, but it is his conclusion which is of special interest here:

As long as the expected learning outcomes are carefully set and defined; as long as the assessment tasks are designed to enable the student to meet those learning outcomes; as long as assessment and grading are carried out fairly and reliably against carefully designed criteria, then the system is deemed to work. Essentially it is a closed system which, like any closed

\footnotetext{
${ }^{2}$ John Biggs, Teaching for Quality Learning at University (Buckingham: SRHE and Open University Press, 1999), 11.

${ }^{3}$ Peter Knight, Being a Teacher in Higher Education. (Buckingham: SRHE and Open University Press, 2002), 1.
} 
system, will tend to encourage and reinforce replication and formulation rather than innovation and origination. ${ }^{4}$

And so as teachers and researchers who are helping to define creative practice within the academy, it is our duty to question this system and to explore more effective alternatives. It is those very qualities of innovation and origination that creative practice-based degree programmes seek to foster in their students, and which are valued by industry; and yet all too often, the challenge of assessing rigorously, transparently and consistently in these subjects means that we fall back on curricula and assessment practices that were not primarily designed to reward the key qualities of successful creative practitioners.*

*By 'successful', we mean a critically-aware practitioner who is capable of producing and sustaining industry-standard work via the deployment of appropriate tools.

\section{A practitioner's stance: the war against the number}

Summative assessment of process-led creative practice modules presents difficulties on numerous levels. We have identified five main areas that require further investigation. We propose that summative assessment is not always appropriate, particularly for first year students, because it does not:

1. encourage deep learning

2. offer tools for students to learn safely how to consciously manage and successfully reproduce processes leading to creative products

3. reflect the process-led nature of creative disciplines

4. accommodate the non-traditional, 'unfinished' nature of creative endeavour

5. mirror real world or industry experience where editorial or directorial dialogue is required

\footnotetext{
${ }^{4}$ Paul Kleinman, Economic and Social Research Council seminar paper. "Beyond the Tingle Factor: Creativity and assessment in higher education,” November 2005, University of Strathclyde, Scotland.
} 


\section{Deep learning}

In our experience, summative assessment tends to result in surface learning. As every student teacher knows, there are significant contrasts between two types of learning: when students experience surface learning they have no process to rely on and therefore lack the ability to reproduce results achieved through their engagement with the module, which is more likely to happen in modules that are outcome-based; deep learning, alternatively, is promoted by process-led modules. The benefits of deep learning and ways to bring it about within academic modules will be discussed shortly.

Norman Jackson echoes these thoughts about assessment of creativity and learning when he writes about the emerging 'Imaginative Curriculum Project':

Student instrumentalism, driven by the teacher's belief that students only learn when they are assessed, inhibits creativity. Narrow, summativelydriven assessment practices and criteria that focus on what is known, which do not recognize the process of learning and how people come to know, or recognize emergent unanticipated outcomes, inhibit creativity. ${ }^{5}$

Thus, summative assessment fails because, notwithstanding their good grades, students do not necessarily know how to be creative individuals. They have not been given the opportunity to experiment, to fail and to try again.

What we mean by a "creative individual” relates to the student's engagement with the process of learning, interpreting different results and not stopping at the first outcome and saying, “Here it is. I have done it.” Kleinman cites Torrance and Rockenstein’s definition, which goes to the core of this argument, since they also see personal creativity as a

process of becoming sensitive to or aware of problems, deficiencies, and gaps in knowledge for which there is no learned solution; bringing together existing information from the memory storage or external;

\footnotetext{
${ }^{5}$ Norman Jackson, Creativity in Higher Education (Lancaster: The Higher Education Academy, PALATINE, 2003), 7
} 
defining the difficulty or identifying the missing elements; searching for solutions, making guesses, producing alternatives to solve the problem... ${ }^{6}$

This definition can be applied to an actor's process of rehearsing or a writer's process of redrafting: the "result" would be a public performance of a dramatic text, or the publication of a piece of creative writing. But it works just as well in relation to the student actor or student writer.

\section{Consciously managing and successfully reproducing creative processes and products}

Summative assessment can cause problems for practitioners working in Academia because the usual 11-week duration of modules can restrict the organic and fluid nature of feedback on practice. Practitioners are expected to work within recently developed assessment frameworks that have not yet fully resolved the issue of assessing experiential work. Summative assessment does not value mistakes and does not allow time for trial and error as traditional academic structures find it difficult to accommodate this unpredictable process.

While we understand that in an industry environment, there are deadlines to be kept, we believe that at such early stages of learning the emphasis ought to be on understanding process, rather than producing an end product. Students setting out on their individual journeys into creative practice are forging their own identities - everyone will have their own, unique, individual process and character. The word “character” in Greek ('kærkt²(r)) translates as "A distinctive mark impressed, engraved, or otherwise formed; a brand, stamp" (Oxford English Dictionary online). The majority (but not all) of our undergraduates are around 18 years old. At this age, they are still defining themselves and are in the process of creating their own unique personalities and defining their own "engraved marks.” Mature students, too, are crafting new identities in new and unfamiliar roles. Therefore, putting a summative mark on their early creative endeavours could well be detrimental: it could impact self-esteem and cause a crisis in confidence in terms of re-connecting with the intimacies of the creative process.

\section{Reflecting the process-led nature of creative disciplines}

\footnotetext{
${ }^{6}$ Paul Kleinman, Design for Learning: A Guide to the Principles of Good Curriculum Design (Lancaster: The Higher Education Academy, PALATINE working papers, 2009), 3.
} 
Like learning a new language, fluency in a creative discipline comes from getting it wrong. Making mistakes can be a powerful tool for making discoveries and gaining insights that may otherwise have remained hidden. If students are fixated on achieving a good grade via summative assessment, they can become strategic in their approach to the module, seeking only those elements that they believe will contribute to a successful academic mark. This can result in a risk-averse attitude that does not allow for exploration and discovery because process appears to be a means to an end, rather than a valuable learning tool in its own right. In traditional academic models of assessment, the "how" is often hidden in the shadows of the "what" - the final product becomes all-important. But if students do not take time to interrogate how something was achieved (or not), then they will have difficulty in replicating successful processes in future. They will not understand why they got something right, or why something didn't work, meaning that they do not progress as autonomous and self-aware practitioners, but rather stay in the dark, believing that successful practice is down to chance or luck, or, even more frustratingly, the "whim” of the teacher.

\section{Accommodating the non-traditional, 'unfinished' nature of creative endeavour}

The assessment of creative practice is a delicate matter since students can find it very difficult not to take the assessment grade as a value judgment on their talent and, in some cases, on themselves. Throughout our teaching practice, we have come to the conclusion that students learn better and more deeply when they are given detailed formative assessment with specific recommendations for improvement. We have also found that students are not clear about how we "calculate” a $68 \%$ grade as opposed to a $70 \%$ grade. The assessment process has been mysterious to them. It is very frustrating to hear comments along the lines of, "my tutor didn’t like my work”. Clearly we need to be transparent with our assessment criteria and involve the student in it, as described by O’Donovan, Price and Rust when they talk about a "shared understanding of standards". 7 This shared understanding of standards could be seen as a very useful way of introducing first year undergraduates not only to our expectations of them but also a common approach and vocabulary which, once established, can provide the key to successful engagement with assessments at more advanced stages of the degree programme. Hopefully, such foundations will allow a common ground to be established

\footnotetext{
${ }^{7}$ B. O’Donovan, M. Price and C. Rust, "Developing student understanding of assessment standards: a nested hierarchy approach,” Teaching in Higher Education 13, no.2 (2008): 205217.
} 
between students and tutors, meaning that in subsequent assessments, it will be clear to the students what '56\%' means. Kleinman, for example, has successfully developed a protocol for discussing and assessing process-led creative work in which tutor and student are cast as co-creators of the grade. ${ }^{8}$

\section{Mirroring real world or industry experience with editorial or directorial dialogue} Ideally, formative assessment would mirror the discussions between a director and an actor (or a writer and an editor) in order to improve a creative output: both director/editor and actor/writer bring pertinent questions to the surface as they work towards a common goal - a creative product that satisfies aesthetic and commercial considerations. The same process benefits student actors or writers who, through discussions with a tutor, learn from their mistakes in order to reach a mutually-understood level of achievement. This process also benefits the student by helping her develop her own set of self-questioning tools. This emulates the director/actor or editor/writer relationship, and will prove an invaluable skill for professional survival in life after University. Such formative assessment processes parallel the idea of the co-constructivist approach to learning, where the assessment criteria come out of a set of shared standards between the learner and teacher (like those shared by the director and actor or publisher and writer). In order to reflect the actor's or writer's experience, the emphasis in a process-led subject should entail having the courage to evaluate work in a formative way, thus ensuring that the student does not feel they are being judged numerically, but that assessment is being used as a creative means to an end.

Such an approach is arguably a more realistic preparation for the creative industries, where the creative practitioner enters a market economy in which the measure of success is not a numeric grade, but 'yes' or 'no' in terms of a commission or contract.

\section{Solution: Deep learning through a module that mirrors creative process - learning by trial and error}

Ideally, we propose re-designing all creative process-based modules to approach what Biggs envisages: assessment and learning outcomes “... in accord in supporting appropriate student learning." 9 At the very least, we argue for the redesign of modules encountered by first year students. We illustrate our proposal with reference to a utopian "blueprint” module, which favours the process-led curriculum. In so doing, we begin with the issue of appropriate

\footnotetext{
${ }^{8}$ Kleinman, "Beyond the Tingle Factor: Creativity and assessment in higher education". ${ }^{9}$ Biggs, Teaching for Quality Learning at University, 11.
} 
assessment and work backwards from this principle in order to create a module that harmonises assessment with learning outcomes and lends itself to formative assessment.

An "ideal” first year creative process-based module (for example, acting or creative writing) needs to be shaped by student response and to adhere to the principles of deep learning; we believe that this can only be achieved by a process-led curriculum. This conclusion fits well with a study by Fraser and Bosanquet, which sees the curriculum as "the student's experience of learning" and asserts that "the shaping of the curriculum ... is often more by negotiation, in terms of having a theoretical point that has to be made ... or process that has to be learned." ${ }^{10}$ Our utopian "blueprint” module adheres to the co-constructivist view expressed by Fraser and Bosanquet: curriculum change happens as an ongoing dialogue between the teacher and student, framed by the more holistic view of the teacher or practitioner. ${ }^{11}$ We pause to note here that the teacher retains authority as a guide and more experienced practitioner. The co-constructivist approach is negotiated on this basis, rather than indulging without reservation every student request.

\section{The utopian "blueprint” module's rationale}

The "blueprint” module's aim is to offer students a practice-orientated experience without losing rigorous critical analysis. In order to anchor our proposal in specific detail, our “blueprint” module will focus on developing students' basic naturalistic acting skills via the tools of Strasberg's Method Acting technique. However, we hope that the transferable nature of these principles is evident - an understanding of character, for example, is also crucial for developing writers.

Teaching Lee Strasberg’s Method as a first year module in Performance Art degrees serves multiple functions. It delivers the subject benchmark's aims and it contributes, through the discovery of a creative self via the acting technique, to the acquisition of wider life and transferable skills such as self-understanding and confidence. Other important life skills that this module would help the student acquire are the ability to be resourceful, the ability to cope with stress and the ability to be persistent despite setbacks, as well as the skills to build relationships. Clearly such attributes are of great value to all graduates, but never more so in this age of austerity when the value of arts and humanities degrees is under such scrutiny. The suggested module would encourage young and sensitive learners (or indeed mature and

\footnotetext{
${ }^{10}$ S. Fraser S. and A. Bosanquet, “The curriculum? That's just a unit outline, isn't it?” Studies in Higher Education 31, no.3 (June 2007): 269-284.

${ }^{11}$ Ibid.
} 
sensitive learners) in their first year to gain more self-knowledge and confidently learn through their mistakes.

We believe the distinctive features of our "blueprint" module are as follows:

\section{No numbers - giving learners the courage to fail}

The module will develop the students' understanding of the role of the actor and, in so doing, offers a deeper understanding of the interpretive artist. The content gives the student the opportunity to engage critically with Strasberg's technique and to have a full experience of its practical application. The module favours the process-led design concept and its focus is to enable students to self-reflect and grow artistically through their learning experience. It aims to foster students' creativity and personal development: accordingly, the module grade is either 'pass' or 'fail'.

The Subject Benchmark Statements (2002) for Dance, Drama and Performance (available on www.palatine.ac.uk) are invaluable tools in terms of providing a common thread. However, while they acknowledge creativity, they fail to address its unexpected, mysterious, organic, exploratory, frustrating and difficult processes. Consequently, when creativity is approached without courage, the interpretation of the creative work can lead to confusion and weak learning. Creativity is linked to passion and motivation and no good learning happens without a hunger to learn. Effective performance evolves out of the rehearsal process which, by its nature, is about change. In this module, focusing on the stepby-step process of creating a character - in which each step is essential - the student learns that perseverance is key to the creative process. A first year student may well be a novice in the rehearsal process. Giving them a mark for what is essentially a rehearsal, and not a finished performance, is unfair and perhaps detrimental to growth. Therefore, this module encourages activities that foster habits and behaviours designed to embed and nurture the student's desire to learn from the "creative mess” of the rehearsal process. This will eventually lead the student to motivate themselves to excel and self-evaluate. In a way we are talking about perseverance, and teaching the student that not giving up when it is "messy" and difficult is essential.

Indeed, Stanislavsky's work was dedicated to finding the technique that leads the actor to find "conscious means to the subconscious". ${ }^{12}$ Damon Knight refines our definition of

${ }^{12}$ Sonja Moore, The Stanislavski System (New York: Penguin, 1984), 10. 
unconscious in relation to creative practice: “it isn’t unconscious, it just has trouble communicating. 'The silent mind' would be better, maybe, or 'the tongue-tied mind'”. ${ }^{13}$ Adopting this approach will promote deep understanding of the process, and not just a mastery of the content of the module. Although we refer here specifically to the actor's process, the ability to recognize and link unconscious creativity to conscious learning is crucial to many artistic practices. We argue that an effective way of raising awareness of, documenting, and reflecting upon this interplay between unconscious and conscious processes is the requirement to produce a learning journal.

Via the journal, the tutor will be able to gauge whether students are able or not to construct meaning out of trials and errors. We believe that this skill is crucial for any student in HE. The focus in our utopian module is on what the teacher and students do, and it does not pre-specify what needs to achieved. Knight sums up this view point when he says that "key messages and learning encounters need to be planned to suffuse the programme."14 Such essential encounters in the proposed module would be designed to engage the students with the exercises, but without looking for a specific outcome.

\title{
A change in weighting of assessment: emphasis on learning journal
}

A key factor influencing the proposed blue-print module is a wish to consider the sensitive balance between practical and written work. While we do not claim that the learning journal is a radically new form of assessment, rather we wish to emphasise its usefulness as a formative assessment tool. It is a relatively new privilege for programme designers to be able to offer 'practice as research' methodologies, as we learn from Brannen's UK-nationally funded Practice as Research in Performance Project (PARIP).

\begin{abstract}
A growing number of Performing Arts departments in Higher Education are now offering higher degrees which place practice at the heart of their research programmes. This represents a major theoretical and methodological shift in the performance disciplines - traditional
\end{abstract}

\footnotetext{
${ }^{13}$ Damon Knight, Creating Short Fiction (New York: St Martins Griffin, 1997), 24.

${ }^{14}$ Peter Knight, "Complexity and Curriculum: a process approach to curriculum-making,” Teaching in Higher Education 6, no.3 (2001): 369-381.
} 
approaches to the study of these arts are complemented and extended by research pursued by the practice of them. ${ }^{15}$

The above encapsulates the challenge for Higher Education institutions offering Performance Art and other practice-based degrees. The ratio between practical and written work is one of the most important concerns of students when they are considering applying to a course (and, indeed, we remember ourselves looking at courses through that lens.) Brannen encapsulates this clearly by stating that most degree programmes in Performance stress "the interdependence of theory and practice, and the majority aim to offer students opportunities to engage with practice in an academic context”. 16

Traditionally, the creative output has carried the higher weighting as the grade rewards the end product. However, what we are suggesting here is that the process, rather than the product, should have the higher weighting. We recommend a $75 \%-25 \%$ split. This means that students can, in effect "fail" the creative output (25\%) and yet still pass the module if the learning journal (75\%) is of appropriate quality. The learning journal will be subject to the traditional summative assessment because this means that we are marking the students' processes and not their final products i.e. not the performance or the creative writing, for example, but how they failed and then "failed better". However, there will not be a percentage 'mark' for this process. The assessor will decide whether the journal has reached a certain benchmark or not: 'pass' or 'fail'.

The aim of the module is to teach a specific acting skill and help students to use it successfully by giving them the specific tools to understand how a performance translates into value judgements such as 'good' or 'bad', to understand consciously how they have come to the result of that process, and to extract lessons for future practice. We emphasise the learning journal in the assessment weighting because it is the tool that will reveal how much, and to what depth, the students have understood their own learning processes. These journals will also further the students’ Personal Development Planning (PDP) skills, contributing to their professional preparation.

Another benefit of emphasizing the journal concerns the potential avoidance of the student's underachievement due to fear or stage fright. A novice performer may have been

15 Rob Brannen,’Balancing Acts: Theatre Teaching in British Higher Education Today,” in Teaching Theatre Today: Pedagogical views of Theatre in Higher Education, ed. L. Fliotsos and G. Medford (New York: Palgrave Macmillan,2004), 209. ${ }^{16}$ Ibid 
well prepared for an assessed performance and clearly had been dedicated to the required rehearsal process but then something happens on assessment day and they freeze, become overly-anxious and accordingly underachieve. Emphasising the journal will also hopefully allow students suffering from stage fright to demonstrate to the tutor that they have undergone a process of deep learning, but that on that single day a set of personal circumstances prevented them from showing this in action. It will also help the student to reflect upon the causes of their anxiety, and to formulate strategies for dealing with it in future performances.

This weighting of assessment more faithfully reflects the evolving 'practice as research' methodologies of creative disciplines, acknowledging that the ability to perform is only one element of creative investigation, as articulated by Robin Nelson. ${ }^{17}$ Therefore it seems illogical to privilege the end product for our students when we 'lecturer-practitioners' do not adhere to this paradigm in our own practice, particularly when the traditional emphasis on final product diminishes, in the eyes of the student, the incentive to 'fail better'.

\section{Maintaining academic rigour}

Although this is very much a process-led approach that does not conform to previous outcome led models, the module retains its academic rigor in terms of meeting set objectives. It is necessary to retain a standard format in order to transfer the essence of the module to colleagues over subsequent years. While we are critical of the misconceived use of outcomeled modules for creative subjects, we do acknowledge the practical usefulness of RCP (Rational Curriculum Planning).

The aim of this module is to help students develop not only specific acting skills, but also their capacity to evaluate their work and the work of others. It follows, therefore, that it will be of great benefit to novice students as a tool for life, and to encourage knowledge of the self, because, as Strasberg puts it, “The actor’s instrument, however, is himself: he works with the same emotional areas which he actually uses in real life.” 18

It is apparent, then, that the student actor's training of her conscious faculties will contribute to the development of a more creative, more confident self. Brian Bates, a psychologist who researches actors' work, exactly echoes these thoughts on the benefit of

${ }^{17}$ Robin Nelson, "Practice-as-research and the Problem of Knowledge" in Performance Research, no.4 (2006): 105 - 116.

${ }^{18}$ Strasberg, A Dream of Passion: The development of The Method,122 
self-knowledge: “There are actors, many actors, who have learned from their work and have integrated the knowledge in an understanding of themselves and others. Personal knowledge is power” ${ }^{\prime 19}$. The student who acquires personal knowledge will own a life skill that will equip her to better succeed in the market place in any chosen field. It therefore follows that the acquisition of self-knowledge is part of a progression that process-led curricula are betterfitted to support.

The module specification form in our case would include the module's learning aims. Our utopian module would maintain the structure of conventional module design within HE, but we suggest a renewed focus on making sure the student has an understanding of individual process as opposed to having acquired the generic skill of "understanding concepts of “. The emphasis is on supporting the processes that fulfil the aims and less so on the outcomes. This is because we contend that in the first year especially, to have specific set outcomes is restrictive and also unpredictable with novice learners in a creative process-led module. The overall aim is for students to begin to gain an understanding of how to learn from error and how not to be afraid of mistakes. In simple terms the aims need to be:

To situate creative practice within the Humanities in HE

To tolerate the fear of failing

To tolerate mess and to see it as productive

To begin the acquisition of processes that will support life-long learning

To understand that the process of failing is a creative outcome in its own right

Students arrive in higher education having been conditioned in summative assessment, and having established their value through 'grades' - even their admission to HE will probably have depended upon the number of 'points' they have received for their learning to date. Indeed, the modular structure of current UK 'A' level qualifications means that students have acquired an in-built fear of failing, because every dropped mark in their summative assessments will have an impact on their future prospects. We see the job of first year undergraduate process-led modules as being part of a process that helps to 'wean' students off their privileging of summative assessment, and to introduce different ways of learning and assessing creative work. Only then, we suggest, are students equipped to deal maturely with summative assessments in the following years.

${ }^{19}$ Bates, Brian, The Way of the Actor: A Path to Knowledge and Power (Boston: Shambhala Publications, 1987), 8. 


\section{Conclusion}

The purpose of this article has been to demonstrate that it is neither advisable nor wise to apply generic assessment procedures and conventional approaches to process -led learning without truly grasping the implications for the discipline. We have emphasised the need for a new type of assessment that fits with our current Higher Education climate where practitioners are also lecturers and researchers and hence we argued that the assessment needs to mirror the 'tools of the trade' that are being taught. Each discipline will suit a different learning strategy and, therefore, the experiential knowledge that comes from teacherpractitioners is essential when designing curricula. We have argued for the benefits of process-led curricula and formative assessment (while adhering to academic learning outcome criteria).

However, we also acknowledge a number of concerns with regard to formative assessment. In the first instance, we acknowledge that many colleagues simply do not have time to re-develop modules to accommodate resource-intensive formative. This is why our module proposal is a "utopian blue-print”. But perhaps our fellow practitioner-lecturers can make small changes towards a more formative mode of assessment, or bear our points in mind when new modules are developed (if they are not already doing so - we do not claim a monopoly on these ideas!). We also acknowledge that advocates for summative assessment may riposte with the criticism that the formative way can be open to favouritism and increase the subjective element of assessment. Is formative assessment more vulnerable to disparity? Certainly, the usual safe-guards and moderation processes need to be put in place. However, in response, we would ask: isn’t summative assessment trying to hide its inevitable subjectivity behind numbers and alignment?

It is also of interest to ask: do students prefer summative assessment? After all, it is familiar to them as they will have experienced it for at least twelve years by the time they start their Higher Education. Do we then adhere to what they wish for as they are now customers of Higher Education? Or do we make the effort to convince them that formative assessment may be alien and difficult at first, but is of far more value to them in the long-run?

We believe we can convince our students of the benefits of formative assessment, especially in the first year. In particular, they may be convinced through the power of example, by giving them a taste of what deep learning is, by being transparent about how we 
are all still learning, and by letting them see our practitioners’ passion for our subjects, a passion for learning and its challenges that is not dependent upon numbers for its value.

Our proposed module, of necessity, addresses many of the focal level achievements in creative subjects and the generic graduate skills that Subject Benchmark Statements require. It offers, through a co-constructivist approach to learning and assessing, a series of learning encounters and activities that emphasise process. In so doing, it seeks to "provide ingredients from which a meal can be created, rather than insist on cooking a recipe”. ${ }^{20}$

${ }^{20}$ Knight, “Complexity and Curriculum: a process approach to curriculum-making,” 2001. 


\section{References}

Bates, Brian. The Way of the Actor: A Path to Knowledge and Power. Boston: Shambhala Publications, 1987.

Biggs, John. Teaching for Quality Learning at University. Buckingham: SRHE and Open University Press, 1999

Duncan, A. "Where will your Degree in Dance and Drama Lead? Making it work." The University of Northampton's Learning and Teaching project with PALATINE (2008). Accessed October 2012 from www.palatine.ac.uk.

Brannen, Rob. "Balancing Acts: Theatre Teaching in British Higher Education Today,” in Teaching Theatre Today: Pedagogical views of Theatre in Higher Education, edited by. L. Fliotsos, and G. Medford, 205-217. New York: Palgrave Macmillan, 2004.

Fraser S. and Bosanquet, A. “The curriculum? That's just a unit outline, isn’t it?” Studies in Higher Education 31 (2007): 269-284.

Jackson, Norman. Creativity in Higher Education. Lancaster: The Higher Education Academy, PALATINE, 2003.

Kleinman, Paul. Economic and Social Research Council seminar paper. "Beyond the Tingle Factor: Creativity and assessment in higher education,” November 2005, University of Strathclyde, Scotland.

----- Design for Learning: A Guide to the Principles of Good Curriculum Design. Lancaster: The Higher Education Academy, PALATINE working papers,2009.

Knight, Damon. Creating Short Fiction. New York: St Martins Griffin, 1997.

Knight, Peter. "Complexity and Curriculum: a process approach to curriculum-making," Teaching in Higher Education 6, no.3 (2001): 369-381.

-----. Being a Teacher in Higher Education. Buckingham: SRHE and Open University Press, 2002.

-----. “Notes on creative curriculum.” Paper presented at the Imaginative Curriculum Project in 2002. The Higher Education Academy, PALATINE working papers, 2005.

Moore, Sonja. The Stanislavski System. New York: Penguin,1988.

Nelson, Robin. 'Practice-as-research and the Problem of Knowledge,' Performance Research 4 (2006):105-116.

O’Donovan, B., Price M. and Rust C. "Developing student understanding of assessment standards: a nested hierarchy approach,” Teaching in Higher Education 13 (2008):205-217.

Strasberg, Lee. A Dream of Passion: The development of The Method. Edited by Evangeline Morphos. New York: Plume Penguin Group, 1988. 
The University of Salford. Programme Specification BA (Honours) Performing Arts. Available at www.salford.ac.uk, 1997.

Quality Assurance Agency for Higher Education. Dance, Drama and Performance Subject Benchmark Statements. Available on www.palatine.ac.uk, 2002. 